\title{
Studying of Diffusion of the Titan in Corundum Ceramics
}

\author{
Vladimir Gurin ${ }^{1}$, Lev Derkachenko ${ }^{1}$, Marcus Schmidt ${ }^{2}$, Ulrich Burkhardt ${ }^{2}$, Juri Grin ${ }^{2}$ \\ ${ }^{1}$ Ioffe Physical-Technical Institute of Russian Academy of Sciences, St Petersburg, Russian Federation; ${ }^{2}$ Max Planck Institute for \\ Chemical Physics of Solids, Dresden, Germany. \\ Email: vladimir.gurin@mail.ioffe.ru
}

Received December 30 ${ }^{\text {th }}, 2010$; revised March 28 $8^{\text {th }}, 2011$; accepted May $10^{\text {th }}, 2011$.

\begin{abstract}
For increase in hardness (durability) and fire resistance (stability to melts metals) corundum ceramics on the basis of $\mathrm{Al}_{2} \mathrm{O}_{3}$ authors of the present work have suggested to protect for the first time its surface stronger and fire-resistant coverings, for example, from $\mathrm{TiB}_{2}$. In work results of high-temperature diffusion $\mathrm{TiB}_{2}$ in a surface of plates from $\mathrm{Al}_{2} \mathrm{O}_{3}$ are shown. For the first time the cathodoluminescence (CL) method for identification and a condition of atom Ti after diffusion is used, in for an establishment of its quantity electron probe microanalysis (EPMA). Durability increase defined a method microindentification by means of a pyramid of Knoop and strength at a bend. Researches have shown perspectivity of hardening of a surface corundum ceramics and use of the above-stated methods for studying of results of diffusion.
\end{abstract}

Keywords: Corundum Ceramics, Covering from Titanium Diboride, Catodoluminescence

\section{Introduction}

Modern the materials technology is characterized by search new and optimization of known ceramic compositions (in a general sense-compounds of metals with nonmetals). The basic share thus make oxides materials, though the quantity oxygen-free (on the basis of oxygen-free refractory compounds-borides, carbides, nitrides and silicides of metals and nonmetals) ceramics recently increases. Are used thus and various protective a covering for ceramics [1-4], including oxides. So, in work [4], for example, for increase stable properties of a composite on the basis of corundum coverings from $\mathrm{TiB}_{2}, \mathrm{ZrC}, \mathrm{B}_{4} \mathrm{C}$, and $\mathrm{WC}$ have been used. As it is known, one of the strongest and cheap ceramic is the ceramics on the basis of sapphire. One of ways of its further increase durability and fire-resistant properties is introduction in its surface of strengthening impurity a method of high-temperature diffusion.

Thus, as have shown researches, such coverings co-operate at a heat with a surface of such composite, partially or completely turning to difficult compounds and solid solutions - depending on a thickness of a covering, a way of its drawing and the subsequent thermal processing. There is a formation of various zones on depth, in which diffusion covering elements, as a rule, their components-metals.

\section{Materials and Methods}

\subsection{Materials}

In the present work diffusion $\mathrm{Ti}$ in ceramics on the basis of pure sapphire has been investigated. Layer $\mathrm{TiB}_{2}$ has been put on a surface of ceramic plates $(5 \times 5 \times 1 \mathrm{~cm})$, and then they have been subjected thermal processing in argon atmosphere at $1500^{\circ} \mathrm{C}-1700^{\circ} \mathrm{C}$ during $\sim 27-48$ hours. As a result in sofis a layer some zones on depth to 500 micron and more, containing various quantities $\mathrm{Ti}$ (Figure 1) were formed. Zones consist of sapphire grains the part from which is covered by a layer containing $\mathrm{Ti}$. Thus in such layer probably formation of various compounds and the solid solutions [4], which identification presents considerable difficulties.

\subsection{Research Diffusion a Layer in Ceramics}

Samples of such ceramics after high-temperature diffusion have been investigated by electron probe microanalysis (EPMA), local visible cathodoluminescence (CL) and microindenting by means of a pyramid of Knoop and strength at a bend. 
(a)

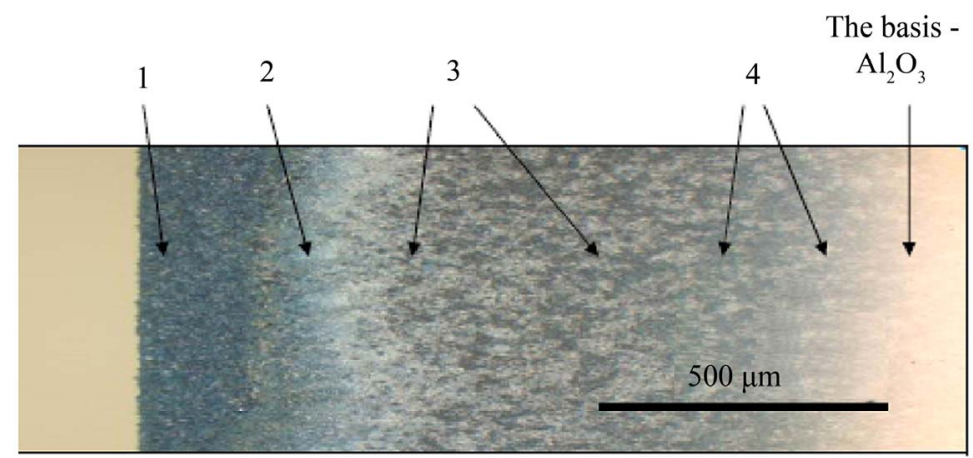

The Decrease of the Quantity Ti

from $0.4-0.1$ to $0.01-0.00$ atomic part $\mathrm{Ti}$

(b)

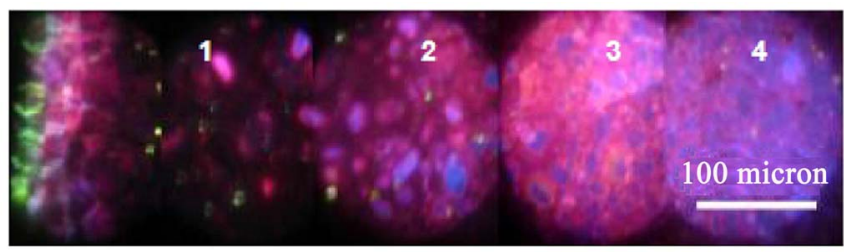

Figure 1.(a) The general view cross-section corundum ceramic plate with a covering of $\mathrm{TiB}_{2}$ after termoprocess $\left(1700^{\circ} \mathrm{C}\right)$ at fast heating. 1) a layer of solidified $\mathrm{TiB}_{2} ; 2$ ) a layer like "necklace"; 3) a layer of a little amount of small grains; 4) a layer of a considerable quantity of small grains, located before pure ceramics; (b)The general view of areas of the basic layers in which content of $\mathrm{Ti}$ was determined by the $\mathrm{CL}$ analysis. The four layers show consecutive reduction of the content of $\mathrm{Ti}$ in them. $\mathrm{Ti}$ - rosy; $\mathrm{Al}_{2} \mathrm{O}_{3}$ - blue; diamond - green (left in hole after polishing).

\section{Resalts and Discussion}

\subsection{Microhardness and Strength}

Cross-sections for measurement of microhardness by means of a pyramid of Knoop prepared by a usual technique. For surface polishing samples were used by diamond pastes.

Researches strength characteristics have shown that after diffusion $\mathrm{Ti}$ microhardness of ceramics has increased approximately twice (from $\sim 24.5$ to $\sim 39 \mathrm{GPa}$, that is from $3 \%$ to $58 \%$ [4]). The greatest values of microhardness turned out in 1st and 3rd layers, and the least -in 2nd (see of Figure 1). Such increase is explained sometimes presence polylayers and orientations nanofragments, perpendicular by planes microindetifikation. Durability of samples with a covering on a bend (by a standard technique) has been measured. In comparison with initial, samples with coverings have shown increase in strength at a bend on from 11.5 to $45 \%$ [4].

\subsection{Cathodoluminescence and EPMA}

In an optical microscope it is visible that the initial ceramics consists of separate grains-crystals leicosapphir (Figure 2). Spectra CL in a range from $1.6-2.4 \mathrm{eV}$ have been received with filter JS-17 use. Samples were investigated at energy electrons $15 \mathrm{KeV}$.

In spectra CL characteristic strips connected with dot

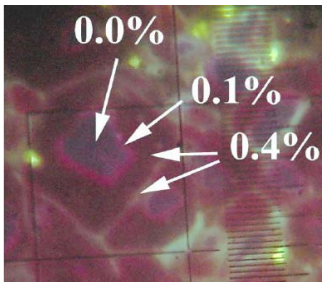

Figure 2. Image CL of ceramics after term process on distance of 200 - 300 micron from a surface -2nd and 3rd layers (see Figure 1) (in drawing maintenance $\mathrm{Ti}$ in weight percent is specified). On six-sided grain are visible: internal bluish area-pure sapphire ( $\mathrm{Ti}-\mathbf{0 . 0} \%$ ) and wide diffusive dark-brown area width to 20 micron) with an internal crimson edge, where $\mathbf{T i}-\mathbf{0 . 1 \%}$, in other part of this area $\mathbf{T i}$ $-0.4 \%$.

defects in sapphire crystals are observed some: a strip with a maximum $3.67 \mathrm{eV}$ connected with a F-centre luminescence in sapphire (vacancy of oxygen with one electron) [5]; a strip with a maximum of intensity $3.1 \mathrm{eV}$, corresponding to a luminescence $\mathrm{R}$ - the centers (anion-action vacancies steams) [6]; a strip with a maximum $2.4 \mathrm{eV}$ connected with steams anion the vacancies which have grasped electrons (the modular centers of F-type) [7]; and a strip with a maximum $1.8 \mathrm{eV}$, corresponding to luminescence $\mathrm{Ti}^{3+}$. The maintenance of impurity $\mathrm{Ti}$ in initial ceramics as has shown method EPMA is less than $0.00 \%$ wt. 
After carrying out of high-temperature diffusion in CL the image it is possible to allocate some the characteristic areas located on various depths from a surface. In the area located deep into on 500 micron large grains with the expressed gradient of maintenance Ti (Figure 2) were observed. Apparently, in this area Ti got into grains on depth to 20 micron. In the centre of the majority of grains there were "single crystal" part of pure sapphire with zero maintenance Ti.

Luminescent properties of the allocated areas in grains (Figure 3) have been investigated. In spectra of sapphire ceramics are allocated a strip with a maximum $3.65 \mathrm{eV}$ and a strip with a maximum $1.8 \mathrm{eV}$. For a strip with a maximum $1.8 \mathrm{eV}$ concentration dependence (Figure 4) has been constructed.

On depth more than 500 micron from a surface the in-

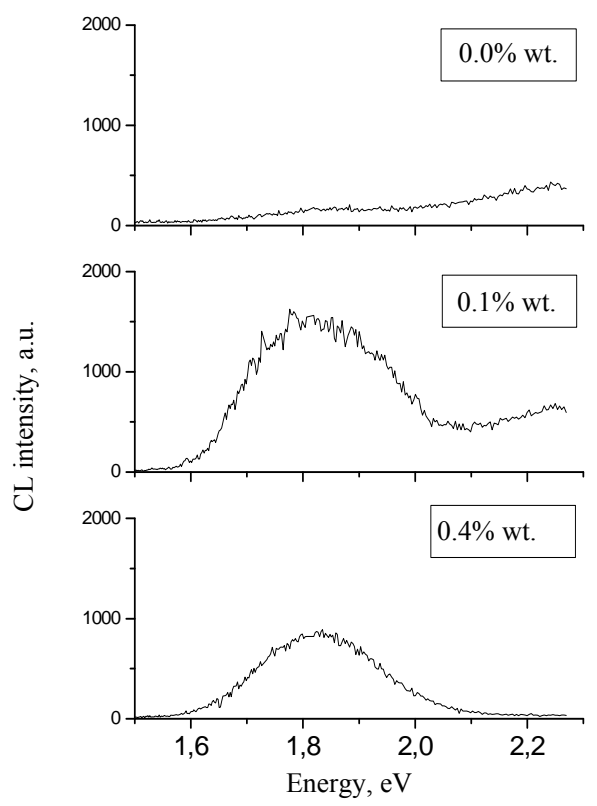

Figure 3. Spectra CL of areas in ceramics with various maintenance $\mathrm{Ti}$.

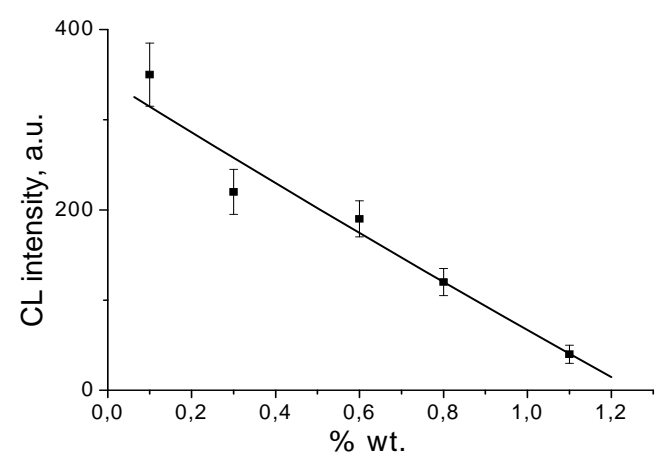

Figure 4. Dependence of intensity CL of a strip with a maximum $1.8 \mathrm{eV}$ from maintenance $\mathrm{Ti}$ in the investigated micro volume. tegrated grains of ceramics also are observed. In this case Ti diffusion in grains on depth no more than 5 microns (Figure 5). On depth more than $3 \mathrm{~mm}$ from a surface maintenance $\mathrm{Ti}$ corresponded to initial ceramics, i.e., $0.00 \%$ wt.

Comparison (on the area of crimson coloring) CL pictures of the crystal sapphire initially alloyed $\mathrm{Ti}$ (with the maintenance nearby $1 \%$ wt., the Figure 6) with the above-stated pictures of distribution Ti in crystal grains (Figure 2 see and Figure 5) shows volume alloying Ti the grains in the crystal sample and superficial alloying on some depth of grains of ceramics from a covering.

Depth of diffusion $\mathrm{Ti}$ in ceramics volume (to $1-3 \mathrm{~mm}$ depending on time of heat treatment and a thickness of a covering from $\mathrm{TiB}_{2}$ ) on usages exceeds depth of diffusion Ti in single crystal grain of sapphire under the same conditions. This anomaly is caused by that diffusion $\mathrm{Ti}$ passes in ceramics on intersize to borders. Then from borders of grains there is diffusion $\mathrm{Ti}$ to their centre on internal dispositions and cracks (area to maintenance $\mathrm{Ti}$ of $0.4 \%$ wt.). Ti reachesborder of single crystal grain of sapphire with the low maintenance of dispositions anddiffusion on depth of an order of 1 micron (maintenance $\mathrm{Ti}$ in this area of $0.1 \% \mathrm{wt}$.). In the grain centre zeromaintenance Ti remains.

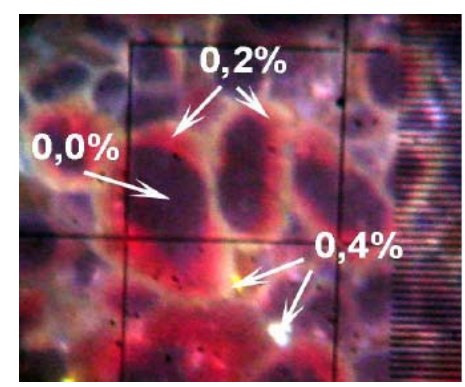

Figure 5. Image CL of ceramics after term process on distance more than $\mathbf{5 0 0}$ microns from a surface (in the end of 3rd layer-see Figure 1). Grains with dark-blue the middle (Ti - $0.0 \%)$ and sites with diffuse $\mathrm{Ti}$ - from 0.2 to $0.4 \%$ and no more than 5 micron are visible width.

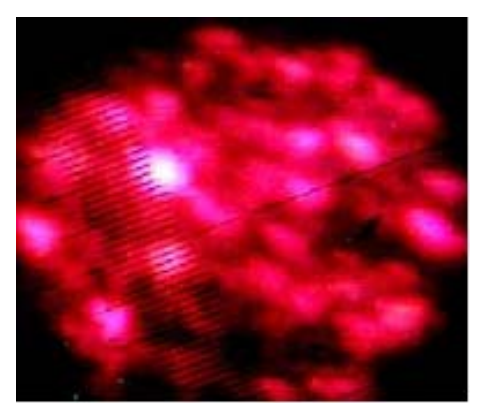

Figure 6. General view CL of a picture of single crystal grains of the sapphire alloyed Ti ( 1\% wt.). Uniform distribution $\mathrm{Ti}$ is characterized by uniform coloring of grains. 


\section{Summary}

Thus, in the present work results of high-temperature diffusion $\mathrm{Ti}$ from $\mathrm{TiB}_{2}$ in a surface pure corundum ceramics for the first time are shown:

1) depending on a temperature mode it is formed diffusions a layer with various depth (to $500 \mu \mathrm{m}-3 \mathrm{~mm}$ ) in which some zones differ;

2 ) at transition from a surface deep into the sample, maintenance $\mathrm{Ti}$ in zones decreases with $\sim 0.4$ to $0.00 \% \mathrm{wt}$. (It is established with the help visible cathodeluminescence);

3) also can be defined and depth of penetration $\mathrm{Ti}$ in a surface of grains of sapphire in the form of ion $\mathrm{Ti}^{+3}$ (it is maximum to $20 \mu \mathrm{m}, \mathrm{CL}$ );

4) Knoop microhardness after thermodiffusion increases more, than in 1.5 times.

Samples with coverings have shown increase in strength at a bend on from $11.5 \%$ to $45 \%$ [4] in comparison with initial samples.

In summary it is possible to notice that there are real prospects of improvement of physicomechanical properties of a surface of ceramics for the account of ceramic coverings with the improved properties.

\section{Acknowledgements}

Authors consider as the pleasant debt to express gratitude to doctors M. V. Zamoryanskaya, E. V. Ivanova, and V. M. Krymov for the help in work.

\section{REFERENCES}

[1] "Materials Technology of Refractory Compounds: Achievements and Problems," Proceedings of Grigorij V. Sam- sonov Member, Internal Conferences, Frantsevich Institute for Problems of Materials Science of National Academy of Sciences of Ukraine, Kiev, Ukraine, 27-29 May 2008, 224 Pages (in Russian).

[2] G. V. Kalinnikov, R. A. Andrievsky, V. N. Kopylov and D. Louzguine, "Properties Nanostructural and Amorphous Films of System TiB2-B4C," Physics of the Solid State, Vol. 50, No. 2, 2008, pp. 360-363 (in Russian).

[3] I. A. Podchernjaeva, "Structure and Properties of Composite Electrospark, Laser and Magnetron Deposited AIN $-\mathrm{TiB}_{2}$ Coatings," Powder Metallurgy and Metal Ceramics, Vol. 40, No. 9-10, 2001, pp. 501-508. (in Russian).

[4] V. N. Gurin, A. B. Sinani, L. I. Derkachenko, V. A. Trunov, G. P. Zajtsev and V. M. Krymov, "Some Ways of Hardening of a Surface Corundum Ceramics," Refractories and Industrial Ceramics, No. 8, 2008, pp. 47-53. (in Russian).

[5] V. S. Kortov, I. I. Milman, S. V. Nikiforov and V. E. Pelenev, "The Mechanism of a Luminescence of the F-Centers in Anion-Defective Single Crystals Aluminum Ocsid," Physics of the Solid State, Vol. 45, No. 7, 2003, pp. 1202-1208. (in Russian).

[6] A. V. Puyats, M. J. Springis and J. A. Valbis, "On the Nature of the Violet Luminescence in Quenche $\alpha-\mathrm{Al}_{2} \mathrm{O}_{3}$ Single Crystals," Physica Status Solidi (A), Vol. 62, 1980, pp. 85-87. doi:10.1002/pssa.2210620162

[7] M. J. Springis and J. A. Valbis, "Visible Luminescence of Colour Centres in Sapphire," Physica Status Solidi (B), Vol. 123, 1984, pp. 335-343. doi: $10.1002 / \mathrm{pssb} .2221230136$ 